\title{
Chapter 17 \\ Floor Effects or Compensation of Social \\ Origin? The Relation Between Divorce and Children's School Engagement According to Parents' Educational Level
}

\author{
Nele Havermans, Gray Swicegood, and Koenraad Matthijs
}

\begin{abstract}
This chapter uses multi-group structural equation models to investigate how the mediators between divorce and school engagement differ according to parents' educational level. Previous studies have failed to address which processes underlie this potential moderating role of parents' educational level and have reported conflicting results. Based on the Leuven Adolescent and Family Study data $(\mathrm{N}=7035)$, our results show that children with lower educated parents are more negatively affected by divorce than children of highly educated parents and that this result cannot be explained by the lower availability of family resources in the group of children with lowly educated parents, whereas family resources are important mediators for children with medium and highly educated parents. Overall, the findings provide more nuanced evidence on how the experience of divorce varies between children of different socioeconomic backgrounds.
\end{abstract}

Keywords Divorce $\cdot$ Education $\cdot$ Social inequality $\cdot$ Structural equation models · Family relationships

\subsection{Introduction}

Divorce is becoming increasingly prevalent among the lower social classes in most Western countries and regions, including Flanders (Belgium) the focal site for this study (Härkönen and Dronkers 2006). Because there is a negative association between parental divorce and children's educational outcomes (Amato 2010),

N. Havermans $\cdot$ G. Swicegood $(\triangle) \cdot$ K. Matthijs

KU Leuven, Leuven, Belgium

e-mail: nele.havermans@ @uleuven.be; gray.swicegood@kuleuven.be;

koen.matthijs@kuleuven.be 
divorce can be one of the mechanisms in the intergenerational reproduction of social inequality: children of lower educated parents are at a higher risk of experiencing parental divorce which in turn may negatively affect their future educational and socioeconomic outcomes (McLanahan 2009; McLanahan and Percheski 2008). The role of divorce in intergenerational transmission of social inequality will also be determined by any moderating effects of parents' socioeconomic background. Some studies find that the consequences of divorce are stronger for children of lower educated parents. This implies that divorce deepens existing social divides in society (McLanahan 2004). Other studies however, report that divorce affects children of higher educated parents more than children of lower educated parents (e.g. Martin 2012; Bernardi and Boertien 2016). The latter findings hint that divorce may function as an equalizer in society.

In this study, we address how and why the relation between divorce and children's educational outcomes may differ according to parents' social background. We investigate two core research questions: (1) does the relationship between divorce and children's school engagement differ according to parents' educational level; and (2) what factors might explain variation in the relationship between divorce and children's school engagement according to parents' educational level? These research questions are investigated on cross-sectional data of the Leuven Adolescent and Family Study data $(\mathrm{N}=7035)$.

This study contributes to the research literature in three ways. First of all, it explicitly examines processes that explain why divorce may affect children with a certain socioeconomic background more than others. To our knowledge, Martin (2012), Augustine (2014), and Bernardi and Boertien (2016) are the only (published) studies which investigate these processes. Their findings show that especially income and parenting characteristics explain heterogeneity in the divorce effect between children of different socioeconomic backgrounds. Second, we focus on the outcome variable school engagement. This important outcome has not yet been studied with respect to the moderating role of parents' educational level, as most studies focus on some variant of academic achievement (Bernardi and Radl 2014; Martin 2012). Third, this is the first study that uses multi-group structural equation models to investigate how the mediators of the relation between divorce and child outcomes differ between certain socioeconomic groups. Multi-group structural equation models have the advantage that they are more parsimonious than models with a large number of interaction effects.

\subsection{Literature Review}

School engagement is the core dependent variable in this study. This non-cognitive educational outcome has received much research attention recently. Studies have shown that school engagement is linked to a number of educational outcomes, such as school attendance, academic achievement, educational aspirations, and enrollment in higher education (Fredricks et al. 2004). School engagement is usually 
defined as a multidimensional concept, consisting of emotional, behavioral and cognitive engagement. Emotional engagement refers to children's affective reactions to class and school in general. Behavioral school engagement relates to conduct in school, involvement in learning and academic tasks, and participation in schoolrelated activities. Cognitive engagement refers to investments in learning and selfregulation (Fredricks et al. 2004). School engagement is a malleable characteristic that results from the interaction between individual and context, such as the family, school and peers. The correlates of school engagement are very similar to those of academic achievement (Fredricks et al. 2004). In this study, we focus on the impact of the family context, and more specifically the impact of divorce and family resources, on school engagement.

Children with divorced parents tend to have lower school engagement than children with continuously married parents (Havermans et al. 2014). In the following, we discuss three factors that underpin this relationship. First, there is the direct psychological impact when children experience family dissolution. The departure of one parent from the household can be painful and stressful for children. They may experience feelings of loss, anger and rejection after the initial separation (Kelly and Emery 2003). This can interfere with children's engagement and achievement in school. Second, the lower availability of financial and social family resources (i.e. quality of family relations) after family dissolution is posited as a strong mediator in the relation between parental divorce and the educational outcomes of children (Sun and Li 2011). Children with divorced parents tend to have fewer financial resources available to them than children with married parents, because the departure of a parent often decreases the total household income. This can interfere with the learning activities of children in a number of ways: (1) there is less money to invest in children's educational career (e.g. school, books) (Brooks-Gunn et al. 1995); (2) economic deprivation can lower parents' and children's educational expectations which can lead to lower school engagement (Astone and Mclanahan 1991); and (3) economic deprivation is often associated with a lower quality of the parent-child relationship and more parental conflict (Conger et al. 2010). In addition to financial resources, the availability of social resources in families with divorced parents tends to be lower. Children with divorced parents have on average less contact with their parents than children with married parents (Amato 2010). Moreover, the strength of the parent-child relationship may also be lower for children with divorced parents (Havermans et al. 2014). Additionally, conflicts between parents do not always end after a divorce (Musick and Meier 2010). Parental conflict is related to lower parental involvement, less effective parenting, and a poorer parent-child relationship. These can lower children's academic success and engagement in school (King and Sobolewski 2006; Murray 2009). The third, final factor that underpins the relation between divorce and children's school engagement is selectivity. Certain inherent characteristics of parents or children may be direct causes of dysfunctional family patterns and divorce, and of lower school engagement (Sigle-Rushton et al. 2014). Parents' educational level (and factors associated with this) is often mentioned as a potential selection mechanism, because it is related to both the risk of parental divorce and children's school engagement (McLanahan and Percheski 2008). As the 
educational gradient of divorce becomes more negative in most western countries, children of lower educated parents are becoming more likely to live in a non-intact family (Härkönen and Dronkers 2006). Children of lower educated parents tend to have lower academic achievement and school engagement than children of higher educated parents (Astone and Mclanahan 1991).

In addition to the evidence that children with divorced parents have more negative educational outcomes than children with continuously married parents, recent studies have investigated whether this relation differs according to parents' educational level. Some studies report that especially children of lower educated parents are negatively affected by divorce (Albertini and Dronkers 2009; McLanahan 2004). This is explained by the 'social origin compensatory hypothesis' (Bernardi and Radl 2014). Socioeconomic deprivation tends to be stronger among lower educated divorced parents, as lower educated parents have fewer opportunities on the labor market, obtain a lower income and live in lower-quality housing (McLanahan 2004; Musick and Mare 2004; Bernardi and Boertien 2016). Furthermore, lower educated parents have on average less interpersonal skills, time and other resources to help children cope with divorce-related changes, and to maintain a quality parent-child relationship after divorce (Augustine 2014; Cooper et al. 2009; Mandemakers et al. 2010; McLanahan 2004). Higher educated parents can buffer their children from such negative consequences of divorce. Their high educational level helps them to minimize the loss of financial resources after divorce and their higher interpersonal skills can help them to support children and maintain a good relationship with them.

Conversely, other studies report that negative consequences of divorce are stronger for children whose parents have a high socioeconomic background and thus diminishes inequalities between children (Fischer 2007; Martin 2012). This is explained by the 'floor effect hypothesis' (Bernardi and Radl 2014): children of lower educated parents are less affected by divorce as they already start with lower levels of academic achievement, parent involvement and financial resources. Children of higher educated parents are expected to experience a reduction in time and money parents can invest in them (Bernardi and Radl 2014) and a decrease in their parents' educational expectations after divorce (Martin 2012). A divorce can thus interfere with the competitive advantage children of higher educated parents have in the educational system (Bernardi and Radl 2014).

The extant literature is somewhat inconclusive, with some studies supporting the 'floor effect hypothesis' and other studies supporting the 'social origin compensatory hypothesis'. These mixed results could be explained by the research context and the operationalization of parental socioeconomic background. First, the context of the study can influence research findings. Bernardi and Radl (2014) have shown that in countries with an early selection into educational tracks (such as Belgium) the divorce effect is stronger for children of lower educated parents, whereas in countries with a different educational system, children of higher educated parents are more affected by divorce. However these authors do not formulate an explanation for how the educational system might influence the moderating role of parents' socioeconomic background. Second, the operationalization of parents' socioeconomic 
background can also influence research findings (Bernardi and Boertien 2017). Fischer (2007) found that the moderating effects of maternal and paternal educational level diverge when simultaneously included in the analytical model. A high level of maternal resources is related to a weaker divorce effect because these maternal resources protect children from the negative consequences of divorce ('social origin compensatory hypothesis'). Conversely, a high level of paternal resources is related to a stronger divorce effect because the resources that are 'lost' after divorce are often the resources of the father ('floor effect hypothesis'). These findings need to be approached with caution, because high multicollinearity in models that include maternal and paternal educational levels work against definitive results (Grätz 2015). Furthermore, it should be taken into account that children in shared residence arrangements have access to both maternal and paternal resources.

This study investigates how and why the relation between divorce and children's educational outcomes can differ according to parents' social background. Based on the literature review, we test two competing hypotheses: the social origin compensatory hypothesis and the floor effect hypotheses. Following the social origin compensatory effect hypothesis $(\mathrm{H} 1)$, we expect that the relation between divorce and school engagement is more negative for children of lowly educated parents (H1a) and that this can be explained by the stronger negative relation between divorce and the availability of financial and social family resources for children of lowly educated parents (H1b). The floor effect hypothesis (H2) claims that the relation between divorce and school engagement is more negative for children of highly educated parents $(\mathrm{H} 2 \mathrm{a})$ and that this can be explained by the stronger negative relation between divorce and the availability of financial and social family resources for children of highly educated parents (H2b).

\subsection{Data and Methods}

\subsubsection{Leuven Adolescent and Family Study 2008-2012}

The data for our analysis are from the first four rounds of the Leuven Adolescent and Family Study (LAFS) 2008-2012. LAFS is a repeated cross-sectional study, collected in yearly rounds since 2008 in Flanders, the Northern part of Belgium, by the Family and Population Studies research team of the University of Leuven (www. soc.kuleuven.be/lago). The LAFS sampling strategy has two stages (Vanassche et al. 2012). First, secondary schools are selected by a purposive, disproportional stratified sampling technique to increase the response rate at the school level. Second, classes of pupils in the selected schools are surveyed. The distribution of sex (male/female), year (first to seventh year) and educational track (academic track, technical track, vocational track) strongly resembles the total school population in Flanders (Vanassche et al. 2012). In total, 7035 pupils between 11 and 19 years old in 44 secondary schools are surveyed. 


\subsubsection{Variables}

\subsubsection{Dependent Variable: School Engagement}

The school engagement scale consists of 12 items that are measured on a 5-point scale (Brutsaert 1993). Children were asked to what degree they agreed with statements regarding their behavioral, emotional and cognitive engagement with school. Behavioral engagement is measured with items such as making the effort to complete homework and being persistent and eager to learn. Emotional items are linked to their feelings about school, such as showing interest or disinterest in school and being focused or distracted in class. Cognitive items tap the psychological investment in learning, such as looking up additional information on subject material. Because there is a considerable conceptual overlap between the three dimensions, an operationalization into separate scales is complicated. Consequently, most studies use a single general scale of school engagement (without distinguishing between the dimensions), or examine only one or two dimensions (often emotional and behavioral engagement) (Fredricks et al. 2004). In the operationalization of school engagement, we also integrate the three dimensions in one multidimensional concept of school engagement.

\subsubsection{Grouping Variable: Parents' Educational Level}

We did not include both mother's and father's educational level in the models for two reasons. Firstly, these two variables are highly correlated ( $78 \%$ of children have parents with the same educational level). Secondly, we want to take the residential arrangement of the child into account, because this influences the access to parental resources after divorce. If parents are still together, we take the highest educational level of both parents into consideration (Buis 2013). In case of divorce and sole custody, the educational level of the residential parent is considered. In case of a divorce and joint custody, the highest educational level of both parents is considered. The variable measuring parents' educational level consists of three categories: low educational level (<ISCED 3; 4\%), medium (ISCED 3-4; 27\%), and high (>ISCED 4; 59\%). Bivariate analyses clearly show that parents' educational level is related to the incidence of parental divorce. Children with a lowly or medium educated parent are more likely to live in a non-intact family than children with a highly educated parent: $42 \%$ of children with lowly educated parents have divorced parents, compared to $33 \%$ of children with medium educated parents and $21 \%$ of children with highly educated parents $\left(\chi^{2}=133.377 \mathrm{df}=2, \mathrm{p}=0.000\right) .{ }^{1}$

\footnotetext{
${ }^{1}$ We did robustness tests with other specifications of educational level (mean educational level, lowest educational level). They all produced similar findings.
} 


\subsubsection{Independent Variables: Family Resources and Divorce}

Financial family resources are measured by the frequency of financial problems within the family. This frequency is indicated on a four-point scale: $1=$ never; 2 = seldom; 3 = sometimes; and $4=$ regularly. For children with divorced parents, this question is asked in relation to both the mother and the father. The financial situation of the mother is used in the analyses when children are in her custody. The financial situation of the father is used when children are in his custody. The mean financial situation of both parents is considered for children in joint custody. The average score on the financial situation variable is 1.70 .

Social family resources are measured via three indicators: the quality of the relationship between children and their mother; the quality of the relationship between children and their father; and parental conflict at the moment of the interview. The quality of the relationship between children and their parents is measured by the Network Relationships Inventory scale of eighteen items (Furman and Buhrmester 1985). Parental conflict is measured via the Conflict Awareness Scale (Grych and Fincham 1993) which measures the intensity of parental conflict at the time of the interview.

The marital status of children's parents is coded as a set of dummy variables. Children are asked whether their parents are (1) married and cohabiting; (2) cohabiting, but not married; (3) divorced after marriage; (4) separated after cohabitation; (5) married, but not cohabiting; (6) single, never cohabited. Children with at least one deceased parent $(1.7 \%)$ are excluded from the analyses. Only a very small proportion of children have parents who are cohabiting without marriage $(1.7 \%)$ or who have separated after cohabitation (3.6\%). Given that the consequences of a separation after cohabitation are very similar for children to those of a divorce in Europe (Amato 2004), we make no distinction between children with cohabiting parents and children with married parents, and between children with divorced parents and children with separated parents. Children whose parents are divorced, separated, single or not cohabiting are coded one on the dummy variable 'parental divorce'. The other categories are coded zero. One quarter of the children (26.5\%) experienced a parental divorce. This proportion corresponds to official estimates of the proportion of Flemish children experiencing parental divorce (Lodewijckx 2005). Other divorce-related characteristics, such as time since divorce, stepfamily formation or custody arrangements, are not included in the analyses, because they can only be measured for children with divorced parents and would therefore confound with the divorce "effect" in the analyses.

\subsubsection{Control Variables}

We include sex, age, educational track, and Belgian nationality as control variables. For sex, girls are coded 1 and boys $0.54 \%$ of the respondents in the research sample are girls. Age is included as a continuous variable centered on its mean of 15 . We control for educational track by including a dummy variable measuring whether the 
child follows the academic track in school $(57 \%)$ or the technical/arts/vocational track $(43 \%)$. The academic track is aimed at academically oriented pupils and prepares them for participation in higher education. Most children start in this track and are directed to the technical or vocational track when they do not reach certain academic standards. The final control variable is Belgian nationality, as a proxy of the migration background of children. This is measured by a dummy variable $(0=$ no, $1=$ yes $) .8 \%$ of the pupils in the sample have a non-Belgian nationality. These children are mostly first-generation immigrants, as second-generation immigrant children often have the Belgian nationality. A table with descriptive values for the dependent, independent and control variables is available on request with the authors.

\subsubsection{Multi-Group Structural Equation Models}

Multi-group structural equation models are performed on the LAFS data. Maximum likelihood estimators with robust standard errors are used to correct for the clustering of the respondents in schools. The estimators use full information maximum likelihood estimation to deal with missing value. The models are constructed in two steps. First, multi-group confirmatory factor analyses are conducted to specify the measurement of the latent concepts (school engagement, mother-child relationship, father-child relationship, parental conflict) across the three groups. The factor structure, factor loadings and item intercepts are constrained to be equal across the three groups of children. This 'scalar equivalent' model implies that mean differences of latent concepts are the result of substantial differences between groups, and not of different interpretations of the questions or different response styles (Raju et al. 2002). The unstandardized factor loadings ( $>$.40) and fit indices of the null model are available on request with the authors. The fit indices of the scalar equivalent model $(\mathrm{CFI}=0.919 ; \mathrm{TLI}=0.917 ; \mathrm{RMSEA}=0.051 ; \mathrm{SRMR}=0.052)$ show that this model fits the data sufficiently. In a second step, the relations between the latent and observed variables are included into the model. The analytical model is presented in Fig 17.1. We specify an indirect path via the financial and social family resources. Also, a path between financial resources and social resources is included, because families with high financial means generally have less parental conflict and better parent-child relationships (Conger et al. 2010). Furthermore, the model includes a direct path between divorce and children's school engagement. This estimate should pick up the direct psychological impact of divorce, as well as the indirect relationship via omitted mediators and the spurious association due to selectivity. The control variables are also included in the model. Because we expect these relations to differ between the groups, we do not constrain the structural effects to be equal across groups. We execute Wald chi-square tests to examine whether effect sizes are significantly different between groups. We report this in the results section, the Wald chi square test values for all parameter estimates are available on request. 


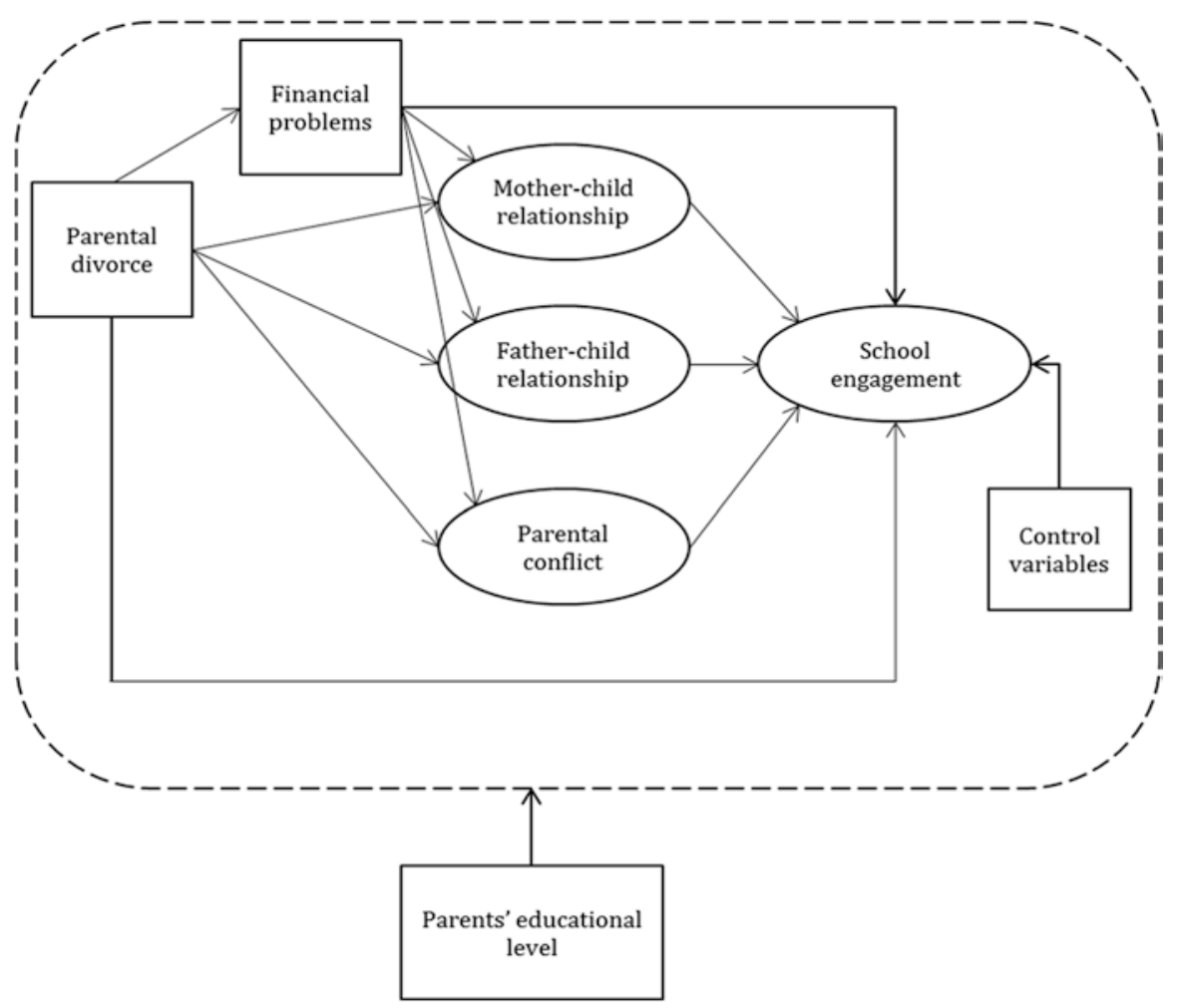

Fig 17.1 Analytical model of the multi-group structural equation model

\subsection{Results}

In the group of children with the least educated parents, parental divorce has a negative direct relationship with children's school engagement (Tables 17.1 and 17.2). A good mother-child relationship is related to more engagement in school. Educational track is the only control variable that is significantly related to school engagement in this group: children in the technical track are less engaged in school than children in the academic track. With regard to the mediating variables, the results show that parental divorce is associated with a lower quality of the mother-child and fatherchild relationship and more financial problems. Financial problems are in turn related to more parental conflict in this group (Table 17.2). There is a small indirect association between divorce and school engagement via a poorer mother-child relationship, but the total indirect effect is not significant (Table 17.1).

For children with medium educated parents, school engagement is positively associated with the quality of the mother-child and father-child relationship. Girls with medium educated parents have higher levels of school engagement than boys. Furthermore, children in the technical track are less engaged than children in the 
Table 17.1 Unstandardized estimates and standard errors for direct and indirect effects of parental divorce on school engagement in multi-group structural equation model

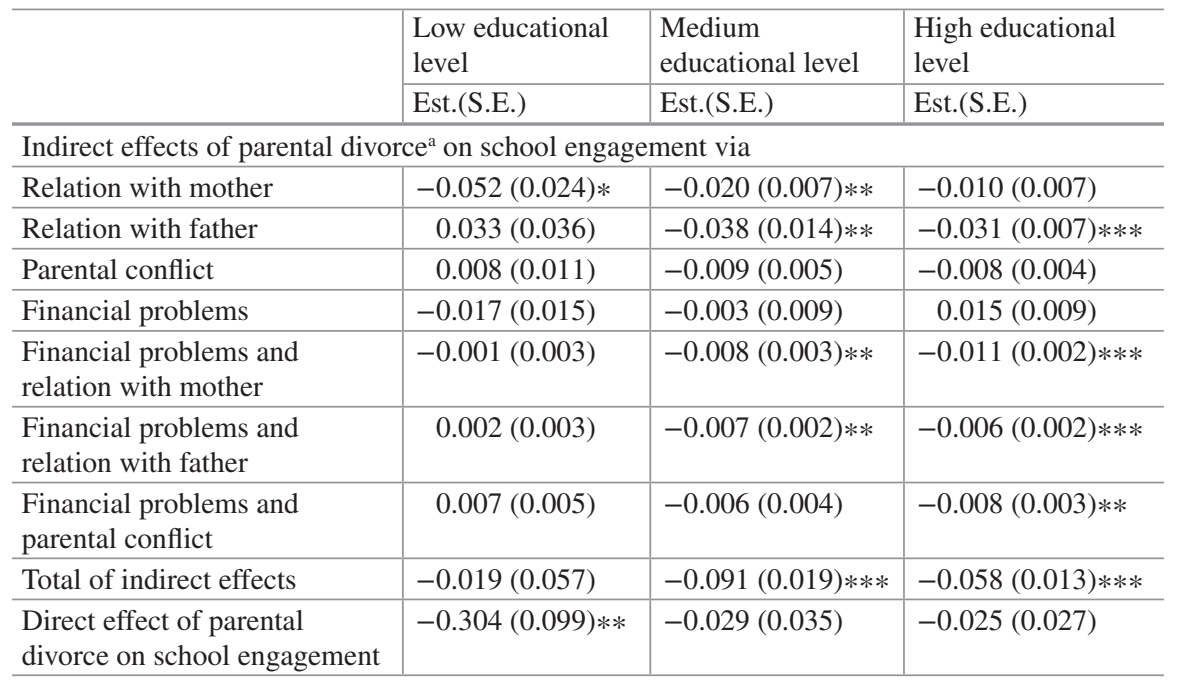

Notes: $\mathrm{N}=7035 . * \mathrm{p} \leq 0.05 ; * * \mathrm{p} \leq 0.01 ; * * * \mathrm{p} \leq 0.001$

Source: LAFS 2008-2012

aParental divorce: $0=$ no, $1=$ yes. $\mathrm{CFI}=0.88 ; \mathrm{TLI}=0.87 ; \mathrm{RMSEA}=0.05$

academic track in this group. Children with the Belgian nationality have lower school engagement than children with a non-Belgian nationality. This is in line with previous studies that have reported that first-generation immigrant children are more engaged in school than native children or later-generation immigrant children (e.g. Motti-Stefanidi and Masten 2013). With regard to the mediating variables, a parental divorce and financial problems both decrease the quality of the motherchild and father-child relationship, and they are associated with an increased frequency of parental conflict. Financial problems are higher in non-intact families (Table 17.2). The total indirect relation between divorce and school engagement is significant in this group, and it operates via poorer father-child and mother-child relationships, the indirect link between financial problems and parental conflict, and between financial problems and the parent-child relationship variables (Table 17.1).

In the group of highly educated parents, school engagement is positively related to the mother-child and father-child relationship. Girls with highly educated parents have more school engagement than boys with highly educated parents. Pupils in the academic track are also more engaged in school than pupils in the technical and vocational track. Finally, children with a non-Belgian nationality report more school 
17 Floor Effects or Compensation of Social Origin? The Relation Between Divorce...

Table 17.2 Unstandardized estimates and standard errors for multi-group structural equation model

\begin{tabular}{|l|l|l|l|}
$\begin{array}{l}\text { Low educational } \\
\text { level }\end{array}$ & $\begin{array}{l}\text { Medium } \\
\text { educational level }\end{array}$ & $\begin{array}{l}\text { High educational } \\
\text { level }\end{array}$ & $\begin{array}{l}\text { Significant } \\
\text { differences } \\
\text { between groups? }\end{array}$ \\
\hline Est. (S.E.) & Est. (S.E.) & Est. (S.E.) & netwen
\end{tabular}

Dependent variable: school engagement

\begin{tabular}{|c|c|c|c|c|}
\hline $\begin{array}{l}\text { Parental } \\
\text { divorce }^{\text {a }}\end{array}$ & $-0.304(0.099) * *$ & $-0.029(0.035)$ & $-0.025(0.027)$ & $\begin{array}{l}\text { Yes, between } \\
\text { low-high }{ }^{\circ}\end{array}$ \\
\hline $\begin{array}{l}\text { Financial } \\
\text { problems }\end{array}$ & $-0.051(0.043)$ & $-0.008(0.021)$ & $0.029(0.018)$ & $\begin{array}{l}\text { Yes, between } \\
\text { three groups* }\end{array}$ \\
\hline $\begin{array}{l}\text { Relation } \\
\text { with mother }\end{array}$ & $0.141(0.054) * *$ & $0.153(0.025) * * *$ & $0.194(0.022) * * *$ & No \\
\hline $\begin{array}{l}\text { Relation } \\
\text { with father }\end{array}$ & $-0.055(0.057)$ & $0.070(0.023) * *$ & $0.079(0.017) * * *$ & No \\
\hline $\begin{array}{l}\text { Parental } \\
\text { conflict }\end{array}$ & $0.080(0.052)$ & $-0.054(0.033)^{\circ}$ & $-0.065(0.025) * *$ & $\begin{array}{l}\text { Yes, between } \\
\text { low-medium }\end{array}$ \\
\hline $\operatorname{Age}^{\mathrm{b}}$ & $-0.024(0.018)$ & $-0.012(0.011)$ & $-0.008(0.007)$ & No \\
\hline $\operatorname{Sex}^{\mathrm{c}}$ & $0.112(0.078)$ & $0.161(0.039) * * *$ & $0.129(0.022) * * *$ & No \\
\hline $\begin{array}{l}\text { Educational } \\
\text { track }^{\mathrm{d}}\end{array}$ & & & & No \\
\hline Technical & $-0.328(0.105) * * *$ & $-0.157(0.057) * *$ & $-0.126(0.037) * * *$ & \\
\hline Vocational & $-0.058(0.100)$ & $-0.070(0.061)$ & $-0.116(0.042) * *$ & \\
\hline $\begin{array}{l}\text { Belgian } \\
\text { nationality }\end{array}$ & $-0.065(0.169)$ & $-0.179(0.070) *$ & $-0.167(0.042) * * *$ & No \\
\hline \multicolumn{5}{|c|}{ Dependent variable: financial problems } \\
\hline $\begin{array}{l}\text { Parental } \\
\text { divorce }^{\mathrm{a}}\end{array}$ & $0.337(0.090) * * *$ & $0.439(0.050) * * *$ & $0.508(0.043) * * *$ & $\begin{array}{l}\text { Yes, between } \\
\text { low-high }^{\circ}\end{array}$ \\
\hline \multicolumn{5}{|c|}{ Dependent variable: relation with mother } \\
\hline $\begin{array}{l}\text { Parental } \\
\text { divorce }^{\mathrm{a}}\end{array}$ & $-0.367(0.108) * * *$ & $-0.132(0.052) * *$ & $-0.050(0.039)$ & $\begin{array}{l}\text { Yes, between } \\
\text { medium-high }\end{array}$ \\
\hline $\begin{array}{l}\text { Financial } \\
\text { problems }\end{array}$ & $-0.024(0.069)$ & $-0.119(0.027) * * *$ & $-0.108(0.017) * * *$ & No \\
\hline
\end{tabular}

Dependent variable: relation with father

\begin{tabular}{l|c|c|c|l}
\hline $\begin{array}{l}\text { Parental } \\
\text { divorce }\end{array}$ & $-0.610(0.119) * * *$ & $-0.542(0.072) * * *$ & $-0.388(0.047) * * *$ & $\begin{array}{l}\text { Yes, between } \\
\text { three groups** }\end{array}$ \\
\hline $\begin{array}{l}\text { Financial } \\
\text { problems }\end{array}$ & $0.270(0.082)$ & $-0.216(0.021) * * *$ & $-0.147(0.019) * * *$ & No \\
\hline
\end{tabular}


Table 17.2 (continued)

\begin{tabular}{l|l|l|l|l}
\hline & $\begin{array}{l}\text { Low educational } \\
\text { level }\end{array}$ & $\begin{array}{l}\text { Medium } \\
\text { educational level }\end{array}$ & $\begin{array}{l}\text { High educational } \\
\text { level }\end{array}$ & $\begin{array}{l}\text { Significant } \\
\text { differences } \\
\text { between groups? }\end{array}$ \\
\cline { 2 - 5 } & Est. (S.E.) & Est. (S.E.) & Est. (S.E.) & No \\
\hline $\begin{array}{l}\text { Dependent variable: parental conflict } \\
\begin{array}{l}\text { Parental } \\
\text { divorce }\end{array}\end{array}$ & $0.096(0.138)$ & $0.172(0.052) * * *$ & $0.120(0.046) * *$ & No \\
\hline $\begin{array}{l}\text { Financial } \\
\text { problems }\end{array}$ & $0.270(0.082) * * *$ & $0.261(0.030) * * *$ & $0.245(0.023) * * *$ & No \\
\hline
\end{tabular}

Source: LAFS 2008-2012

Notes: $\mathrm{N}=7035 .{ }^{\circ} \mathrm{p}<0.10 ; * \mathrm{p} \leq 0.05 ; * * \mathrm{p} \leq 0.01 ; * * * \mathrm{p} \leq 0.001$. CFI $=0.88$; TLI $=0.87$; RMSEA $=0.05$. Dependent variable of the equation is presented in italics

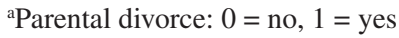

${ }^{\mathrm{b}} \mathrm{Age}$ is centered around mean of 15

'Sex: $0=$ boy, $1=$ girl

${ }^{\mathrm{d}}$ Educational track: reference group is academic track

${ }^{\mathrm{e} B e l g i a n}$ nationality: $0=$ no, $1=$ yes

engagement than Belgian children. Regarding the mediators in the model, parental divorce is related to more financial problems and parental conflict, and with a lower quality of the father-child relationship. Financial problems have a negative relation with the mother-child and father-child relationship and a positive relation with the frequency of parental conflict (Table 17.2). The total indirect connection between divorce and school engagement is significantly negative in this group. It is mediated via the father-child relationship and the indirect effects of financial problems on the parent-child relationship and parental conflict (Table 17.1).

Overall, these findings suggest that the pathways of divorce differ according to parents' educational level. The availability of resources after divorce explains the relation between divorce and children's school engagement more in the groups of children with medium and highly educated parents, than in the group of children with lowly educated parents. Three findings support the 'floor effect hypothesis' (H1) that claims that the relation between divorce and the availability of resources is stronger for children with higher educated parents. First, the relation between divorce and financial resources is stronger for children of highly educated parents than for children of lowly educated parents. Second, financial problems are significantly related to the quality of the mother-child and father-child relationship for children with medium and highly educated parents, but less so for children of lowly educated parents. Third, there is no significant indirect path in the group of children with lowly educated parents via the lower availability of family resources. Conversely, the finding that highly educated parents are better at protecting the father-child relationship from the negative consequences of parental divorce than medium educated parents, supports the 'social origin compensatory hypothesis' (H2) which claims that higher educated parents have more resources after divorce than lower educated parents. 


\subsection{Conclusion}

In this study, we aimed to determine how and why the relation between divorce and children's school engagement differs according to parents' educational level. A first important finding of this study is that the relation between divorce and school engagement is significantly more negative for children of lowly educated parents than for children of higher educated parents. This finding is in line with the social origin compensatory hypothesis (H1a) and supports the idea that divorce is related to 'diverging destinies' of children: children of lowly educated mothers and fathers have a higher risk of experiencing a parental divorce and they experience more negative outcomes after divorce than children of highly educated parents (McLanahan 2004). Our results appear to contradict those studies that report a stronger divorce effect for children of higher educated parents (e.g. Bernardi and Radl 2014; Martin 2012). This may be a function of the research context. Flanders (Belgium) has a stratified educational system with an early selection into educational tracks. Bernardi and Radl (2014) demonstrated that in such a system the educational outcomes after divorce for children of lower educated parents are more negative than for children of higher educated parents. Another explanation may be found in the operationalization of parents' educational level: we have chosen to focus on the highest educational level of the residential parent, and not on the educational level of mother and/or father. Boertien and Bernardi (2017) have shown that the operationalization of socioeconomic background (mother or father) has a strong impact on the research findings regarding the heterogeneity of the divorce effect.

The multi-group structural equation models presented above provide insights into the group-specific processes linking divorce and school engagement. Given that we found that the association between divorce and school engagement is stronger for children of lowly educated parents, we expected that the availability of resources is a particular important mediator for this group (H1b). This hypothesis is supported by the results for the father-child relationship: highly educated parents are more successful in buffering the potential negative consequences of divorce in this domain. Conversely, three findings support the alternative 'floor effect hypothesis' (H2b): the effect size of divorce on financial problems is considerably stronger for children of medium and highly educated parents than for children with lowly educated parents; the relation between financial problems and the parent-child relationship variables is only significant for children with medium and highly educated parents; and the indirect relation of divorce on school engagement via family resources is not significant for children with lowly educated parents.

Overall, the research findings show that the availability of resources is an important determinant of school engagement of children in non-intact families with medium and higher educated parents. For children with lowly educated parents, we find that the association between divorce and school engagement cannot be explained by the lower resources availability as for children with medium and highly educated 
parents. Other mechanisms that may account for this relation in the group of children with lowly educated parents, include a direct psychological effect, the operation of other mediators or selectivity. First of all, the direct psychological effect of divorce may be stronger for children of lower educated parents. Children from a low socioeconomic background tend to interpret stressful situations, such as parental divorce, more often as threatening than do children of a higher socioeconomic background (Chen et al. 2004). Secondly, other mediating factors may be more suitable for explaining the divorce effect in this group. For instance, custody arrangements, stepfamily formation and family instability after divorce are in general more problematic for children of lower educated parents (McLanahan 2009; Sodermans et al. 2013). These factors are not included in the analyses, as they can only be measured for children with divorced parents and would therefore confound with the divorce effect. Also, parents' social network may explain why the negative relation between divorce and school engagement is stronger for children of lower educated parents; higher educated parents tend to have a larger social network to draw upon when confronting problems associated with divorce (Augustine 2014). Thirdly, selectivity may also underlie the direct effect of divorce for children of lowly educated parents. There may be some confounding selection factors that are related to both parents' educational level, divorce risk and children's educational outcomes, such as the parents' physical and psychological health (Sigle-Rushton et al. 2014). Exploring these mechanisms specifically for children with lowly educated parents can be a fruitful direction for future research, especially in the development of policy recommendations.

The generalizability of the findings is subject to some limitations. First of all, we use cross-sectional data making it more difficult to draw causal inferences. For instance, information on family resources is only available at the time of the interview, and there is no information on the loss of resources during the divorce process. Longitudinal data could ameliorate this limitation. Second, our data do not include an indicator of children's school performance, a more cognitive dimension of educational outcomes. Nevertheless, we would expect similar findings, as school engagement is strongly correlated to academic achievement.

The findings of this study have some implications for policymakers. First of all, policy interventions should take children's socioeconomic background into account: children from different socio-economic positions might have been different needs in terms of the implications of parental separation on their school engagement. Second, we found that family relationships are important mediators of the relation between divorce and children's school engagement in all socioeconomic groups. Improving family relationships after divorce can therefore help children to adjust to their new family structure, regardless of their socioeconomic background.

Acknowledgement This chapter benefited from the support of the Centre for Population, Family and Health (CPFH) at the University of Antwerp and the Flemish Agency of Innovation and Entrepreneurship (Grant number:140069), which enabled Open Access to this chapter. 


\section{References}

Albertini, M., \& Dronkers, J. (2009). Effects of divorce on children's educational attainment in a Mediterranean and Catholic Society: Evidence from Italy. European Societies, 1(11), 37-41.

Amato, P. (2004). Reconciling divergent perspectives: Judith Wallerstein, quantitative family research, and children of divorce. Family Relations, 52(4), 332-339.

Amato, P. (2010). Research on divorce: Continuing trends and new developments. Journal of Marriage and Family, 72(3), 650-666.

Astone, N., \& Mclanahan, S. S. (1991). Family structure, parental practices and high school completion. American Sociological Review, 56(3), 309-320.

Augustine, J. M. (2014). Maternal education and the unequal significance of family structure for children's early achievement. Social Forces, 93(2), 687-718.

Bernardi, F., \& Boertien, D. (2016). Understanding heterogeneity in the effects of parental separation on educational attainment in Britain: Do children from lower educational backgrounds have less to lose? European Sociological Review, 32(6), 807-819.

Bernardi, F., \& Boertien, D. (2017). Explaining conflicting results in research on the heterogeneous effects of parental separation on children's educational attainment according to social background. European Journal of Population, 33(2), 243-266.

Bernardi, F., \& Radl, J. (2014). The long-term consequences of parental divorce for children's educational attainment. Demographic Research, 30(61), 1653-1680.

Brooks-Gunn, J., Klebanov, P., \& Liaw, F. (1995). The learning, physical, and emotional environment of the home in the context of poverty: The infant health and development program. Children and Youth Services Review, 17(1/2), 251-276.

Brutsaert, H. (1993). School, gezin en welbevinden: Zesdeklassers en hun sociale omgeving. Leuven: Garant.

Buis, M. L. (2013). The composition of family background: The influence of the economic and cultural resources of both parents on the offspring's educational attainment in the Netherlands between 1939 and 1991. European Sociological Review, 29(3), 593-602.

Chen, E., Langer, D., Raphaelson, Y., \& Matthews, K. (2004). Socioeconomic status and health in adolescents: The role of stress interpretations. Child Development, 75(4), 1039-1052.

Conger, R. D., Conger, K. J., \& Martin, M. J. (2010). Socioeconomic status, family processes, and individual development. Journal of Marriage and Family, 72(3), 685-704.

Cooper, C. E., McLanahan, S. S., Meadows, S. O., \& Brooks-Gunn, J. (2009). Family structure transitions and maternal parenting stress. Journal of Marriage and Family, 71(3), 558-574.

Fischer, T. (2007). Parental divorce and children's socio-economic success: Conditional effects of parental resources prior to divorce, and gender of the child. Sociology, 41(3), 475-495.

Fredricks, J. A., Blumenfeld, P. C., \& Paris, A. H. (2004). School engagement: Potential of the concept, state of the evidence. Review of Educational Research, 74(1), 59-109.

Furman, W., \& Buhrmester, D. (1985). Children's perceptions of the personal relationships in their social networks. Developmental Psychology, 21(6), 1016-1024.

Grätz, M. (2015). When growing up without a parent does not hurt: Parental separation and the compensatory effect of social origin. European Sociological Review, 31(5), 546-557.

Grych, J., \& Fincham, F. (1993). Children's appraisals of marital conflict: Initial investigations of the cognitive-contextual framework. Child Development, 64(1), 215-230.

Härkönen, J., \& Dronkers, J. (2006). Stability and change in the educational gradient of divorce. A comparison of seventeen countries. European Sociological Review, 22(5), 501-517.

Havermans, N., Botterman, S., \& Matthijs, K. (2014). Family resources as mediators in the relation between divorce and children's school engagement. The Social Science Journal, 51(4), 564-579.

Kelly, J., \& Emery, R. (2003). Children's adjustment following divorce: Risk and resilience perspectives. Family Relations, 52(4), 352-362. 
King, V., \& Sobolewski, J. M. (2006). Nonresident fathers' contributions to adolescent well-being. Journal of Marriage and the Family, 68(3), 537-557.

Lodewijckx, E. (2005). Kinderen en scheiding bij hun ouders in het Vlaamse Gewest. Een analyse op basis van Rijksregistergegevens. Brussels: Centrum voor Bevolkings- en Gezinsstudies.

Mandemakers, J. J., Monden, C. W. S., \& Kalmijn, M. (2010). Are the effects of divorce on psychological distress modified by family background? Advances in Life Course Research, 15(1), $27-40$.

Martin, M. (2012). Family structure and the intergenerational transmission of educational advantage. Social Science Research, 41(1), 33-47.

McLanahan, S. S. (2004). Diverging destinies: How children are faring under the second demographic transition. Demography, 41(4), 607-627.

McLanahan, S. S. (2009). Fragile families and the reproduction of poverty. The Annals of the American Academy of Political and Social Science, 621(1), 111-131.

McLanahan, S. S., \& Percheski, C. (2008). Family structure and the reproduction of inequalities. Annual Review of Sociology, 34(1), 257-276.

Motti-Stefanidi, F., \& Masten, A. S. (2013). School success and school engagement of immigrant children and adolescents. European Psychologist, 18(2), 126-135.

Murray, C. (2009). Parent and teacher relationships as predictors of school engagement and functioning among low-income urban youth. The Journal of Early Adolescence, 29(3), 376-404.

Musick, K., \& Mare, R. D. (2004). Family structure, intergenerational mobility, and the reproduction of poverty: Evidence for increasing polarization? Demography, 41(4), 629-648.

Musick, K., \& Meier, A. (2010). Are both parents always better than one? Parental conflict and young adult well-being. Social Science Research, 39(5), 814-830.

Raju, N. S., Laffitte, L. J., \& Byrne, B. M. (2002). Measurement equivalence: A comparison of methods based on confirmatory factor analysis and item response theory. Journal of Applied Psychology, 87(3), 517-529.

Sigle-Rushton, W., Lyngstad, T., Andersen, P., \& Kravdal, Ø. (2014). Proceed with caution? Parents' union dissolution and children's educational achievement. Journal of Marriage and Family, 76(1), 161-174.

Sodermans, A. K., Vanassche, S., \& Matthijs, K. (2013). Post-divorce custody arrangements and binuclear family structures of Flemish adolescents. Demographic Research, 28(15), 421-432.

Sun, Y., \& Li, Y. (2011). Effects of family structure type and stability on children's academic performance trajectories. Journal of Marriage and Family, 73(3), 541-556.

Vanassche, S., Sodermans, A. K., Dekeyser, G., \& Matthijs, K. (2012). Methodologische documenten Leuvens Adolescenten en Gezinnenonderzoek. Leuven: Centrum voor Sociologisch Onderzoek.

Open Access This chapter is licensed under the terms of the Creative Commons Attribution 4.0 International License (http://creativecommons.org/licenses/by/4.0/), which permits use, sharing, adaptation, distribution and reproduction in any medium or format, as long as you give appropriate credit to the original author(s) and the source, provide a link to the Creative Commons license and indicate if changes were made.

The images or other third party material in this chapter are included in the chapter's Creative Commons license, unless indicated otherwise in a credit line to the material. If material is not included in the chapter's Creative Commons license and your intended use is not permitted by statutory regulation or exceeds the permitted use, you will need to obtain permission directly from the copyright holder.

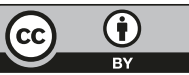

